\title{
O TRABALHO FEMININO ASSALARIADO NAS FÁBRICAS DE PESCADO NA GALÍCIA
}

\author{
Susana Maria Veleda da Silva ${ }^{1}$ \\ César Augusto Avila Martins ${ }^{1}$
}

\begin{abstract}
RESUMO - O texto analisa o trabalho feminino nas fábricas de conserva de pescado na Galícia, Comunidade Autônoma da Espanha. A pesquisa objetiva analisar o trabalho feminino assalariado considerando a segregação laboral e as trajetórias de resistências das trabalhadoras. A base conceitual é fundamentada na geografia feminista considerando o patriarcado e o trabalho remunerado com a perspectiva da divisão de trabalho por gênero. As reflexões baseiam-se nas observações de campo e em entrevistas realizadas em 2012, com onze pessoas envolvidas com o setor da indústria de produtos da pesca: trabalhadoras, empresários(as), representantes da associação das empresas e sindicalistas. E também, em cinco entrevistas realizadas entre 1994-1997, com trabalhadoras do setor. Considerando a segregação laboral e as práticas de resistência coletiva, os resultados da pesquisa indicam que o setor mantém o caráter de exploração do trabalho feminino no que se refere aos baixos salários e a pouca perspectiva de ascensão e no uso esporádico da força de trabalho.
\end{abstract}

Palavras chave: Trabalho feminino; fábricas de pescado; patriarcado; gênero.

ABSTRACT - WOMEN's PAID LABOR In GALICIA's Fishing INDUSTRY. This study analyzes women's labor in fish canneries located in Galicia, an autonomous community of Spain. It aims to analyze labor by taking into account job segregation and stories of the female workers' resistance. The conceptual basis is feminist geography, which takes into consideration patriarchy and paid labor from the perspective of the division of labor by gender. Reflection was based on field observations and interviews conducted in 2012 with eleven people involved in the fishery sector namely female workers, executives, representatives of companies' associations and union members. Five interviews conducted with female workers between 1994 and 1997 were also included. Taking into account labor segregation and collective acts of resistance, the results of this study show that this sector continues the characteristic exploitation of women's labor regarding low pay and reduced chances for promotion, besides the sporadic use of this labor force.

Keywords: Women's labor; fishing industries; patriarchy; gender.

1 Instituto de Ciências Humanas da Informação, Universidade Federal do Rio Grande, Campus Carreiros, Rio Grande - RS - Brasil CEP 96203-900, Rua São Borja, 465 - Cassino Rio Grande - RS CEP 96205-160. E-mail: sucaveleda@gmail.com; cavilamartins@yahoo.com.br 
RÉSUMÉ - LE TRAVAIL SALARIE DES FEMMES DANS LES USINES DE POISSONS DE GALICE. La présente recherche considère la ségrégation du travail et les voies de résistance des travailleuses. Sa base conceptuelle est fondée sur la géographie féministe et considère le patriarcat et le travail rémunéré dans une perspective de division du travail selon le genre. Ces réflexions sont basées sur des observations de champs et des entrevues réalisées en 2012 avec onze personnes appartenant au secteur de l'industrie des produits de la pêche: des travailleuses et des entrepreneurs(euses), des représentants de l'association des entreprises et des syndicalistes; et dans cinq entrevues réalisées entre 1994-1997 avec les travailleuses de l'industrie. Ayant considéré la ségrégation du travail et les pratiques de résistance collective, les résultats de cette recherche indiquent que ce secteur conserve un caractère d'exploitation du travail des femmes, en termes de bas salaires, de peu de perspective d'ascension et d'une utilisation sporadique de la force de travail.

Mots clés: Travail des femmes; usines de poissons; patriarcat; genre.

\section{INTRODUÇÃO}

Na simbiose contraditória das relações entre a afirmação do Estado Moderno e das empresas como agentes que produzem as metamorfoses da hegemonia do capitalismo, $o$ trabalho, foi e é central para compreender os diferentes processos constituidores da vida nas múltiplas escalas (Vainer, 2001). Daí a histórica e constante preocupação de diferentes ciências com sua gênese, organização e da apropriação desigual de seus resultados na lógica de separação entre a compra e a venda da força de trabalho nas distintas regulações estatais e interestatais. Uma das bases das agendas de pesquisa sobre o trabalho é a complexidade polarizada entre aquelas/es que dispõem apenas de suas capacidades de trabalho em seus fragmentos de classe e os poderes concentrados em número reduzido por grupos econômicos detentores da riqueza da maior parte do mundo (Bauman, 2015; Piketty, 2014). A racionalidade criada com a separação entre os proprietários e proprietárias dos meios de produção e os trabalhadores e as trabalhadoras impôs o reordenamento ou a lenta extinção das antigas relações sociais e assumiu uma das formas mais acabadas: a fábrica, controlada por empresas na direção do aprofundamento da divisão técnica com o refinamento do controle científico do trabalho em suas várias matrizes. A lógica fabril com controle do trabalho e as possibilidades de expansão do uso de parcelas da natureza como fontes de energia e de matéria primas para a produção de um número incalculável de mercadorias, transbordou para a organização das cidades e das áreas rurais e penetrou nos recônditos da vida nas diferentes formações sociais.

Uma parte da racionalidade fabril das revoluções industriais e das transmutações de suas matrizes organizacionais, provocaram crises cíclicas nas relações entre as empresas, dessas com o mundo do trabalho e com as regras estatais. O conjunto está conectado com novas dinâmicas nas cidades, com a decadência de algumas atividades e localizações, com a criação e recriação de relações entre e dentro das classes sociais com variados recortes que atingem faixas etárias, grupos étnicos, religiosos, nacionalidades e o sexo. 
O sexo como elemento promotor de desigualdade social que limita e possibilita o acesso e a permanência de mulheres e homens no mundo do trabalho remunerado, somente pode ser categoria de análise quando transformado em gênero, entendido como uma construção social do feminino e do masculino (McDowell \& Sharp, 1997). Os gêneros são valorizados segundo o contexto social a que estão submetidos. Este trabalho adota a perspectiva feminista como teoria explicativa da origem e da permanência da condição desigual de mulheres e homens no trabalho remunerado no modo de produção capitalista, considerando as relações de gênero imersas na prevalência do patriarcado (Pateman, 1988).

Se o ser humano existe no planeta há cerca de 200 mil anos, o sistema patriarcal é recente na história da humanidade, com início entre sete mil e 600 a.C. (Saffioti, 2004). O patriarcado é o sistema base do pacto social, pois o contrato social é também sexual e assegura a dominação dos homens e a sujeição das mulheres, portanto é público e privado. Como elemento constitutivo da história da humanidade, o sistema patriarcal sofreu os impactos do tempo e foi abalado nos seus principais alicerces: a reprodução biológica, a heterossexualidade, o casamento e a família nuclear (Foord \& Gregson, 1986). A separação entre a sexualidade e a reprodução, as técnicas de inseminação artificial, a crescente aceitação e a criação de leis que legitimam uniões homossexuais, a redução no número de casamentos formais e a profusão de novos arranjos familiares para além da família nuclear patriarcal, provocam crises no patriarcado aliadas ao aumento da educação formal das mulheres e o crescente acesso delas ao trabalho remunerado. $\mathrm{Na}$ atual fase do capitalismo, as resistências oriundas de bases materiais e políticas, expressas nos diversos movimentos feministas, criaram condições para a consciência do sistema opressor, mas ainda não foram suficientes para acabar com a sua base material: o trabalho.

A pesquisa objetiva analisar o trabalho assalariado feminino nas fábricas de pescado na Comunidade Autônoma da Galícia no Noroeste da Espanha, considerando a segregação laboral e as trajetórias de resistência das trabalhadoras. O eixo central do artigo é o trabalho feminino entrelaçado com evidências empíricas que resgatam aportes de feministas socialistas, como Heleieth Iara Bongiovani Saffioti (1934-2010) e Iris Marion Young (1949-2006) entre outras pesquisadoras. As reflexões apresentadas baseiam-se em trabalho de campo com visitas nas fábricas, nos sindicatos de trabalhadores(as) e na Asociación Nacional de Fabricantes de Conservas de Pescados y Mariscos (ANFACO-CECOPESCA $)^{\mathrm{i}}$ e, em entrevistas realizadas com pessoas ligadas ao setor da conserva nos períodos de 1994 a 1997 e em 2012 $2^{\mathrm{ii}}$. Justifica-se a importância da ANFACO-CECOPESCA para a pesquisa, pois a mesma foi criada no começo do século $\mathrm{XX}$, num contexto de conflitos entre as empresas de processamento de pescado com as trabalhadoras das fábricas e com os pescadores. A ANFACO tem sede em Vigo, participando ativamente em fóruns internacionais sobre o setor e mantêm um importante centro de pesquisas em conjunto com a Universidade local. Atualmente representa a maior parte e as mais importantes empresas do setor permitindo considerar, no artigo, as fábricas de pescado, conserva ou enlatamento como indústria de produtos da pesca. Os nexos explicativos partem do pressuposto de que é fundamental explicar o trabalho feminino com base no patriarcado, considerando a sua divisão por gênero. 
O texto está organizado em cinco partes. Na primeira introduz-se a temática, delimitando os pressupostos da compreensão sobre as ligações da dinâmica do modo de produção capitalista e sua concretização em formações sociais e os elementos centrais da pesquisa empírica. Na segunda parte, discute-se o argumento conceitual baseado nas relações patriarcais de gênero no capitalismo como uma forma central de exploração do trabalho e da submissão das mulheres. Na terceira parte caracteriza-se o trabalho feminino na indústria de produtos da pesca na Galícia e na quarta, analisa-se a situação das trabalhadoras, considerando a segregação laboral e as trajetórias de resistência coletivas. Por último, traçam-se algumas considerações que apontam os limites e possibilidades para análise do mundo do trabalho com base no feminismo e na análise de gênero no sentido da construção de estratégias que minorem a exploração do trabalho e melhorem as condições de vida.

\section{MARCO TEÓRICO DA PESQUISA}

Quantitativamente há um aumento da presença das mulheres no mercado de trabalho, porém, o incremento não desvela as mudanças qualitativas nas oportunidades de emprego, nas relações e nas condições de trabalho com reflexos especialmente nos salários mais baixos das mulheres em relação aos homens ${ }^{\mathrm{iii}}$. O que explica a opressão e a exploração do trabalho feminino nas fábricas de conserva de pescado, na segunda década do século XXI?

\section{Patriarcado e capitalismo: o trabalho produtivo remunerado das mulheres}

O uso da teoria do patriarcado como possibilidade de explicação universal da opressão e da subordinação das mulheres tem sido questionado pelos estudos feministas através de concepções teóricas e conceituais divergentes. Nas décadas de 1970 e 1980 a abordagem marxista foi questionada por feministas socialistas, que consideravam que apenas as lógicas do mundo do trabalho no capitalismo não explicavam a situação das mulheres. Porém, a aliança entre o patriarcado e o capitalismo explicada em um sistema dual, poderia acabar com o "matrimônio infeliz" entre as duas teorias. Assim, o marxismo tradicional e o feminismo radical poderiam se beneficiar mutuamente (Hartmann, 1980). Para a autora, o patriarcado tem uma base material. Nesta base, um conjunto de relações sociais entre os homens, hierárquica ou não, estabelece ou cria interdependência e solidariedade entre eles e os coloca em situação de dominar as mulheres. Young (1981) contesta a concepção de um sistema dual e afirma que patriarcado e capitalismo são sistemas de dominação que interatuam e se alimentam de modo que garantem a opressão e subordinação da classe trabalhadora e das mulheres. O fundamento do patriarcado é o controle do trabalho das mulheres que as exclui do acesso aos recursos produtivos, o que coloca as relações patriarcais intrínsecas das relações de produção.

A concepção universal do conceito de patriarcado se reforça na incorporação da psicanálise no discurso feminista. Mitchell (1975) considera que o patriarcado é uma estru- 
tura ideológica universal, ainda que cada modo de produção o expresse em formas diferentes. O entendimento a-histórico do patriarcado foi questionado tanto por feministas radicais como as que apostavam nas teorias pós-estruturalistas e pós-modernas (WGSG, 1997). Entende-se que este universal é produzido histórica e geograficamente e, portanto, o conceito é relativo e pauta a própria agenda de ação quando é considerado com uma noção ampliada de poder e de política. Coaduna-se com a posição de Massey (2004) quando considera que o poder relacional produz espaços relacionais, em uma perspectiva em que o privado também é político. Assim, a opressão das mulheres tem, também, bases culturais. $\mathrm{O}$ uso da categoria gênero para rechaçar as atribuições concedidas pelo patriarcado através do processo de naturalização da opressão masculina se alia à necessidade de explicar que o trabalho das mulheres ocupa um lugar central em qualquer sistema de produção e a hierarquia sexual é um elemento crucial em qualquer sistema de dominação (Young, 1981). Assim, a divisão sexual do trabalho com origem na história da humanidade reproduz e mantém o capitalismo e a subordinação das mulheres.

A partir do final da década de 1970, pesquisadoras espanholas como Benería (1979) e Garcia Ramón (1990) contribuíram com estudos feministas sobre a divisão sexual do trabalho. A primeira argumentava que o foco da atividade econômica da mulher tem origem na sua função específica de reprodutora da força de trabalho. A função de reprodutora está na raiz da subordinação das mulheres e determina a participação destas na esfera produtiva. A segunda, ao estudar a agricultura nos países desenvolvidos a partir do enfoque de gênero, concordava com Hartmann (1976), considerando que a divisão sexual do trabalho no modo de produção capitalista é um mecanismo básico para manter a subordinação da mulher.

Nos limites da teoria marxista tradicional a emancipação das mulheres viria com a eliminação da propriedade privada e com a sua efetiva incorporação no trabalho produtivo. Porém a relação entre o aumento da participação feminina no trabalho remunerado não se traduz em imediata emancipação, pois depende do tipo de trabalho e da remuneração, bem como do tipo de participação que desempenham no trabalho reprodutivo, e como o compartem com o/a companheiro/a ou outros membros da família. A presença das mulheres no trabalho produtivo e remunerado está marcada pelas atividades exercidas e apreendidas no trabalho reprodutivo realizado no espaço doméstico especialmente aquelas ligadas com a higiene, limpeza, assistência aos filhos e aos idosos e a alimentação. A situação representa a condição histórica em que o gênero, entendido como uma construção social do feminino e do masculino, é fator determinante para a participação de mulheres e de homens em determinadas ocupações, constituindo-se na divisão sexual do trabalho. Historicamente, as mulheres ocuparam empregos nos setores de serviços e na indústria têxtil, de vestuário e de fabricação de alimentos e, a partir da década de 1970, por exemplo, na indústria microeletrônica, indicando uma constante segmentação por sexo da força de trabalho (Beneria, 1979; Elson \& Pearson, 1981; Garcia Ramon, 1990; McDowell \& Pringle, 1992; McDowell \& Sharp, 1997).

A segmentação do trabalho por sexo é hierárquica e conduz a uma desvalorização do trabalho feminino refletida na menor remuneração tanto em economias centrais como nas 
periféricas (Aoyama, Murphy, \& Hanson, 2012). Considera-se que o termo divisão sexual do trabalho pode ser reforçado teoricamente, com ênfase numa abordagem feminista, quando o termo sexual é substituído pela palavra gênero. O conceito de divisão do trabalho por gênero reforça a ideia de que, é trabalho toda a atividade realizada no espaço reprodutivo e no produtivo e que a designação por gênero é imprescindível para o capitalismo.

\section{2. $O$ conceito de divisão do trabalho por gênero}

Young propôs o conceito de divisão do trabalho por gênero como um marco analítico que considera as relações sociais materiais de uma formação social histórica particular, a qual constitui-se num sistema único, em que a diferenciação de gênero é um atributo central (Young, 1992). Para a autora:

"El análisis de la división del trabajo opera en el nivel más concreto de las relaciones particulares de interacción e interdependiencia en el interior de una sociedad que la diferencia y convierte en una compleja red. Este análisis describe las divisiones estructurales más importantes entre los miembros de una sociedad según su posición en la actividad laboral, y evalúa el efecto de estas divisiones en el funcionamento de la economía, de las relaciones de dominación y de las estructuras políticas e ideológicas." (Young, 1992, p. 7).

A divisão de trabalho por gênero refere-se a toda a diferenciação estruturada do trabalho em uma sociedade. No capitalismo, a divisão entre o trabalho reprodutivo, como as tarefas domésticas e os cuidados familiares designados às mulheres, e o trabalho produtivo remunerado designado aos homens, fundamenta-se numa concepção patriarcal que reforça o status de dominação masculina através da importância do trabalho produtivo e da desvalorização do reprodutivo e explica o lugar das mulheres na produção. Existe um contrato oculto heteropatriarcal (Pateman, 1988) que sustenta a exploração do trabalho das mulheres.

Portanto, "o capitalismo abriu as portas sim, mas do emprego, pois as mulheres já trabalhavam, havia muito tempo, mais que os homens" (Saffioti, 2000, p. 73). O capitalismo se apropriou do trabalho das mulheres a partir da industrialização ao utilizá-las como força de trabalho nos setores que exigiam habilidades adquiridas no espaço reprodutivo que passaram a ser desvalorizadas. Uma parte das mulheres se transformou em assalariadas e foi incorporada em condição secundária na classe trabalhadora, uma vez que a função principal do gênero feminino estava baseada na sua função reprodutiva.

O efeito positivo desta incorporação se traduz na liberdade de escolha em relação à profissão. $\mathrm{O}$ capitalista necessita de trabalhadores/as qualificados/as e as mulheres que aumentam o número de anos de estudos formais, postergam uniões conjugais e a maternidade, diminuem o número de filhos e tomam consciência de seus direitos, lutando por emancipação política e por melhores condições de trabalho.

Nos últimos três séculos, a incorporação das mulheres e dos homens no mercado de trabalho hegemonizado pelas relações assalariadas foi seletiva. $\mathrm{O}$ capitalismo que pode 
proporcionar as ferramentas para a luta contra a opressão feminina ao mesmo tempo, utiliza a divisão de trabalho por gênero para perpetuar o lucro e a desvalorização do trabalho das mulheres. O caso empírico do artigo, o setor da indústria de produtos da pesca, ilustra a segunda situação. A pesquisa analisou o trabalho feminino em fábricas que realizam majoritariamente o enlatamento de pescado.

\section{O TRABALHO FEMININO NA INDÚSTRIA DE PRODUTOS DA PESCA: AS DELIMITAÇÕES DA PESQUISA}

A produção industrial com base em produtos da pesca é uma das últimas atividades econômicas dependente da extração de um recurso vivo: as diferentes espécies coletadas em diversos ambientes naturais com marcas da sazonalidade. Concomitantemente, há um afastamento da produção do pescado como um meio de vida de populações que anteriormente viviam como pescadores artesanais, proprietárias de instrumentos simples de trabalho e de saberes ancestrais para a produção de armadores e/ou industriais proprietários das embarcações. Ou seja, o pescado tende para se constituir, hegemonicamente, em recurso e matéria-prima industrial com tendência para o aumento da produção aquícola em relação a pesca extrativa.

$\mathrm{O}$ funcionamento do setor industrial pesqueiro encontra limites e possibilidades na lógica contraditória das relações entre os distintos ritmos naturais e os ritmos sociais impostos pelas empresas, em seus conflitos com os produtores de matérias-primas (pescadores, armadores, aquicultores e coletores) com os trabalhadores nos barcos e fábricas e nas regulações estatais. A diversidade de atividades das empresas que realizam a industrialização do pescado pode ser sintetizada na seguinte tipologia: resfriamento, congelamento, salga, defumação, enlatamento, fabricação de óleo e farinha.

Segundo Martins (2006), há uma imprecisão na origem da industrialização do pescado, pois envolve identificar processos difusos ao longo do tempo e de difícil localização. A industrialização do pescado permitiu diminuir a perecibilidade da mais alterável das carnes consumida pelos seres humanos. O processo mais simples de processamento é a secagem realizada desde aproximadamente 4000 a.C. A secagem derivou para a salga e posteriormente para a preparação de conservas em latas e o uso do frio que permitiram o aumento do consumo de pescados.

No setor de processamento de pescado, a matéria-prima representa cerca de 50\% do preço final (Beuren \& Cardoso, 2010) de um enlatado e a força de trabalho no setor de conservas da Espanha representa cerca de 17\% do produto final (Núnez Gamallo, 2006). A elaboração e o processamento do pescado nas fábricas foi e é realizado historicamente por mulheres ${ }^{\text {iv }}$. A riqueza produzida pelo setor de industrialização de pescado tem, no trabalho das mulheres, o seu principal motor.

A Espanha tem relevo internacional na produção de pescado em conservas: cerca de 340 mil toneladas/ano ( $6 \%$ da produção mundial) com posição entre os dez maiores produtores e destaque para a segunda posição na produção de conservas de atum $(12,7 \%)$, 
sendo ultrapassada apenas pela Tailândia ( $31,3 \%$ do total mundial) ${ }^{v}$. As empresas espanholas combinam a escala que permite praticar preços competitivos com estratégias que envolvem a utilização de matéria-prima de diferentes origens e a intensificação da mecanização com a produção de cerca de 4100 formas de apresentação do produto final com diversificações de seus portfólios com a busca de certificações ambientais e de mercados tipificados (Alcubilla, 2012). Conjuntamente, deslocam as suas instalações para os polígonos industriais espanhóis, transformado suas antigas fábricas em fiches industrialles em áreas para negócios imobiliários ou, para outros países, com posições estratégicas para o desembarque do pescado e o acesso a determinados mercados. Neste último caso, estão as fábricas do grupo Calvo em El Salvador e no Brasil, da Jealsa na Guatemala, no Chile e no Brasil e da Salica no Equador. O processo tende para a oligopolização onde as quatro maiores empresas do setor (Calvo, Frinsa, Garavilla e Jealsa Rianxeira), foram responsáveis por $59,23 \%$ das vendas e $64,22 \%$ do volume processado (Alcubilla, 2012).

Os principais estudos empíricos analisam o setor entre o século XIX e o final dos anos de 1970: Carmona Badía (2011) e Vásquez Saavedra (2007) na perspectiva da história econômica e Muñoz Abeledo $(2002,2010)$ considerando as relações de gênero. Estes estudos também têm por base as atividades na Galícia que, no século XIX, concentravam $67,8 \%$ dos barcos, $47,9 \%$ dos estabelecimentos de pesca, salga e conservação de pescado, e 71,8\% dos trabalhadores(as) do setor em relação a Espanha (Diaz de Rábago, 1885).

A importância das mulheres nas atividades de chão de fábrica, como operárias e dos homens, no setor administrativo ou em cargos de direção nas empresas, evidencia quantitativamente a segregação ocupacional por sexo, oriunda da divisão do trabalho por gênero na ordem patriarcal. A situação é constatada nos dados sobre o número de trabalhadores femininos e masculinos nas indústrias derivadas da pesca, desde a década de 1950 (quadro I).

Quadro I - Espanha: fábricas e trabalhadores nas indústrias derivadas da pesca (conservas, salgas, produção de farinhas e óleos) em diversos anos.

Table I - Spain: factories and workers in the fishing industry derived (preserves, cured meats, production of meal and oil) in several years.

\begin{tabular}{|c|c|c|c|c|c|c|c|c|}
\hline \multirow{3}{*}{ Anos } & \multirow{3}{*}{ Fábricas } & \multicolumn{7}{|c|}{ Trabalhadores } \\
\hline & & \multicolumn{3}{|c|}{ Total geral } & \multicolumn{2}{|c|}{$\begin{array}{l}\text { Direção, técnicos e } \\
\text { administração }\end{array}$} & \multicolumn{2}{|c|}{ Operários } \\
\hline & & Total & $\mathbf{H}$ & M & $\mathrm{H}$ & M & $\mathrm{H}$ & M \\
\hline 1952 & 796 & 16449 & 4346 & 12103 & $\ldots$ & $\ldots$ & $\ldots$ & $\ldots$ \\
\hline 1960 & 780 & 19562 & 5255 & 14307 & 1194 & 125 & 4061 & 14182 \\
\hline 1961(1) & 748 & 19299 & 4764 & 14535 & 1170 & 160 & 3594 & 14375 \\
\hline 1971(2) & 498 & 20707 & 5511 & 15196 & 1266 & 263 & 3913 & 14876 \\
\hline 1977 & 421 & 18492 & 4747 & 13745 & 1289 & 310 & 3205 & 13368 \\
\hline
\end{tabular}

Fonte: INE. Estadisticas industriales: industrias derivadas de la pesca. Organização: César Martins.

(1) Médias mensais (2). Exclui dados de Alava, Baleares, Burgos, Palencia, Sevilla e Soria com menos que três fábricas. $\mathrm{H}$ - Homens; $\mathrm{M}$ - Mulheres 
Em 2010, havia na Espanha 552 empresas do setor num total de 886 estabelecimentos ${ }^{\mathrm{vi}}$. A maioria das fábricas (801), possuía até 49 assalariados e apenas onze possuíam mais de 200 trabalhadores. As outras 74 fábricas empregavam entre 50 a 199 trabalhadores. Neste ano, 18571 pessoas estavam ocupadas nas empresas de conserva de pescado espanholas e 13400 na Galícia que, historicamente, concentra as fábricas (Instituto Nacional de Estadística, 2010). Em 2011, a ANFACO-CECOPESCA contabilizou 147 empresas na Espanha e destas, 65 estavam na Galícia e ocupavam 77,72\% dos trabalhadores do setor e respondiam por $75 \%$ em valor setorial.

Em 2012, a maioria das empresas galegas possuía controle familiar com tendência para profissionalização em alguns cargos executivos e força de trabalho majoritariamente feminina. No período de 2000 a 2010, o percentual de mulheres variou entre aproximadamente 60 e $80 \%$ do total dos trabalhadores. Os dados do quadro II indicam que houve uma diminuição de $15 \%$ de participação das mulheres e um aumento de $16 \%$ dos homens.

Quadro II - Total e \% de trabalhadores por sexo com CNAE - 1993/152 e CNAE - 2009/102*, Espanha e Galícia, 2000 e 2010.

Table II - Total and \% of workers by sex with CNAE - 1993/152 and CNAE - 2009/102*, Spain and Galicia, 2000 and 2010.

\begin{tabular}{l|ccc|ccccc}
\hline \multirow{2}{*}{ Ano } & \multicolumn{3}{|c|}{ Espanha } & \multicolumn{3}{c}{ Galícia } \\
\cline { 2 - 8 } & Total & H & M & Total & H & \% & M & \% \\
\hline 2000 & 24600 & 9200 & 15500 & 13000 & 2800 & 21,54 & 10200 & 78,46 \\
2010 & 24800 & 9300 & 15500 & 13400 & 5000 & 37,31 & 8400 & 62,68 \\
\hline
\end{tabular}

Fonte: INE, Encuesta de Población Activa. ${ }^{\star} \mathrm{CNAE}$ 1993: 152 inclui a "Elaboración y conservación de pescados y productos a base de pescado". CNAE 2009: 102 inclui o "Procesado y conservación de pescados, crustáceos y moluscos”. Organização: Susana Maria Veleda da Silva. $\mathrm{H}$ - Homens; $\mathrm{M}$ - Mulheres

Os dados analisados e as entrevistas realizadas com diretores e trabalhadoras das fábricas galegas indicaram que a variação da presença de mulheres e homens é resultado de dois elementos: 1) a execução de processamento de pescado em unidades fabris menores com registros frágeis e fora das grandes fábricas que iniciam a automatização de algumas partes da produção como a limpeza do pescado que era, historicamente, realizada de forma manual pelas mulheres; 2) o deslocamento das fábricas de algumas das maiores empresas de conserva de pescado galegas para a América Latina e África. O processo de transferência de parte da produção com a instalação de fábricas fora da Espanha pode ser exemplificado na mudança da estrutura territorial de três das quatro das maiores empresas galegas (Alcubilla, 2012): a Calvo empregava, em Carballo, 550 pessoas e 300 na fábrica de Esteiro, no município de Muros, enquanto suas unidades no Brasil possuíam 2000 trabalhadores e a de El Salvador, 1 000; a Jealsa de um total de 3500 trabalhadores, empregava entre 300 e 400 na Guatemala, 300 no Chile, 300 no Saara Ocidental (fechada em 2014) e 800 no Brasil, com fábricas em Rio Grande (Rio Grande do Sul) e no Ceará; a Salica com cerca de 2500 trabalhadores, mantinha cerca de 10\% de assalariadas em Bermeo e o restante no Equador ${ }^{\text {vii. }}$. 
No século XXI, as mulheres ainda predominam no chão de fábrica, realizando atividades relacionadas a limpeza e a conservação do pescado em situação semelhante às pesquisas realizadas até à década de 1970 (Muñoz Abeledo, 2010). As atividades nas fábricas apresentam uma relação de trabalho que combina a formalidade através de contratos formais e de tempo indeterminado, com a eventualidade do trabalho temporário e/ou informal em função da sazonalidade e da quantidade da matéria-prima, fragilizando o trabalho feminino. As relações e as condições de trabalho das mulheres nas fábricas de conserva de pescado reproduzem relações de gênero contaminadas por concepções patriarcais que sofreram poucas mudanças nos quase duzentos anos do setor.

A fonte qualitativa da próxima seção assentou nas observações de campo e em onze entrevistas gravadas e transcritas, realizadas em $2012 \mathrm{em}$ seis cidades galegas: Cambados, Poio, Vilagarcía de Arousa, Vigo, Carballo e A Coruña. Os locais das entrevistas foram as fábricas, um bar em Cambados, a sede do sindicato da Confederación Intersindical Galega (CIG) e a ANFACO/CECOPESCA e tiveram tempos de duração diferentes, com uma média de 30 minutos. As entrevistas foram realizadas com pessoas envolvidas no setor de conserva de pescado: quatro trabalhadoras no chão de fábrica (duas delas envolvidas com a atividade sindical); duas mulheres ocupando cargos administrativos de direção; um sindicalista, dois diretores, um empresário e um diretor executivo da ANFACO/CECOPESCA. Também foram utilizadas como fonte de dados, cinco entrevistas realizadas, entre os anos de 1994 e 1997, com trabalhadoras no chão de fábrica da indústria de pescado galega. As entrevistas, gravadas e transcritas e com duração média de 30 a 60 minutos, foram realizadas nas casas das trabalhadoras, localizadas em Cangas, Rianxo, Ribeira e duas na Isla de Arousa.

A leitura das entrevistas transcritas realizadas nos anos de 1990 teve como objetivo metodológico ampliar as informações sobre as trabalhadoras do chão de fábrica. Infere-se que a dificuldade em realizar as entrevistas em 2012, poderia estar relacionada a timidez das mulheres em falar sobre suas vidas e, também, devido ao local da entrevista, a fábrica, podendo ser motivo de intimidação, pois na entrevista realizada em um bar, a entrevistada estava mais à vontade, falando por quase 60 minutos gravados. Buscou-se também, identificar mudanças e permanências nos depoimentos das trabalhadoras. Passados quase vinte anos, entre os anos noventa do século XX e a primeira década do século XXI, observa-se uma situação muito similar no discurso e na situação destas trabalhadoras. Os testemunhos captados nas entrevistas foram contrastados com as observações de campo e com o referencial empírico e documental.

\section{O TRABALHO FEMININO NA INDÚSTRIA DE PRODUTOS DA PESCA: A PERMANÊNCIA DA EXPLORAÇÃO}

Na Espanha, do século XIX ao XXI, as trabalhadoras das fábricas de conserva têm em comum a construção de uma vida de lutas e trabalho árduo por melhores condições laborais, salários dignos, valorização, reconhecimento de seu trabalho e resistência 
frente a exploração e opressão. A pesquisa identificou dois elementos para análise: a segregação laboral e as estratégias de resistência coletiva.

\section{A segregação laboral}

A segregação laboral nas fábricas de conserva de pescado tem como fundamento a divisão do trabalho por gênero, que se consubstancia nas contratações, nas tarefas realizadas, nos salários e nas promoções. As trabalhadoras no pescado começam a trabalhar nas fábricas muito jovens:

"Ay, yo empecé muy jóven! Mire yo le voy a decir los años que llevo de conserva, trabajé en una fábrica de Aldán, empecé a los 14 años." (C, 18/07/1995).

"Yo empecé con 13 años en la fábrica de La Puerta y a los seis meses como no tenía seguro, ni tenía nada me marché para Alfageme a pedir trabajo." (M, 21/05/2012).

$\mathrm{O}$ acesso ao emprego nas fábricas era, ainda é em alguns locais, na juventude, pela influência e indicação de parentes, vizinhas, amigas ou por iniciativa própria. A maioria da força de trabalho mora em áreas limítrofes à fábrica e se forma a partir das habilidades adquiridas no trabalho reprodutivo ou na própria fabrica com outras mulheres. Em várias situações, as empresas contratam trabalhadoras temporalmente ocupadas no trabalho doméstico ou em atividades da agricultura e da pesca e se beneficiam dessa força de trabalho barata e adaptável as suas necessidades. As contratações estão baseadas nas habilidades das mulheres que foram apreendidas no espaço reprodutivo e, portanto, em uma sociedade machista, que sub-valora social e economicamente tais habilidades.

Na década de 1980, Elson \& Pearson (1981, p. 93) observaram que as operárias das maquiladoras mexicanas possuíam os "dedos ágeis" adquiridos no treinamento que receberam de suas mães e outros parentes do sexo feminino desde a primeira infância, nas tarefas socialmente apropriadas para o papel da mulher. Os dedos adestrados das trabalhadoras nas fábricas de conservas também são o resultado do treinamento que receberam nas mesmas condições e abrangem principalmente cozinhar, limpar e cuidar. Como tais habilidades são consideradas inatas, são subvalorizadas pelo empregador e pela sociedade. Ao contrário, as contratações masculinas baseiam-se em aptidões masculinas adquiridas formalmente, na escola ou em cursos como o de mecânica, refletindo-se em diferenças salariais. A baixa escolaridade e a falta de outras oportunidades de trabalho é um dos principais motivos de entrada nas fábricas. Nos anos de 1990, três das entrevistadas não haviam terminado os estudos primários, uma não sabia ler e escrever e outra possuía o ensino médio, enquanto todas as entrevistadas em 2012 possuíam o ensino fundamental.

“(...) Yo me puse a trabajar porque yo no servía para estudiar." (M, 21/05/2012).

“(...) como no quise estudiar...tampoco es que me hiciese economicamente mucha falta... porque en la casa... tenia quince años y no hacia nada tampoco, no queria estudiar, ni aprender a coser." (MC, 13/07/1995).

“(...) antes de los 16 años ya trabajaban en esta empresa, con 14-15, se formaron aquí, y ya trabajaban en esta empresa. De hecho hay gente que lleva 46 años aquí trabajando y son mujeres." (G, 23/05/2012). 
A divisão sexual do trabalho, como toda relação social, é dinâmica. A passagem do processo de acumulação fordista para a acumulação flexível reestruturou e precarizou o mundo do trabalho. $\mathrm{O}$ trabalho nas fábricas de conserva permaneceu praticamente imune às transformações no mundo do trabalho. As mulheres trabalhavam no beneficiamento do pescado desde os primórdios das primeiras fábricas e pouco alteraram a sua situação laboral com as mudanças dos diferentes processos produtivos. Mulheres casadas que trabalhavam no beneficiamento do pescado tinham um salário complementar ao dos maridos ou mesmo dos filhos e reduziam seu tempo na fábrica para fazer as tarefas domésticas. Quando assumiam a chefia familiar, era comum trabalharem na fábrica em turno integral e levarem as filhas para adquirirem habilidades nas tarefas e contribuir com o orçamento familiar. A situação laboral das mulheres pode ser avaliada no processo de inclusão das meninas e das adolescentes na fábrica que ocorria em muitas situações com a execução de tarefas árduas e insalubres como o recolhimento dos resíduos de pescados.

A maioria da força de trabalho tem origem no entorno das fábricas que se situavam historicamente na linha de praia ou na área portuária. Atualmente algumas fábricas foram deslocadas para os polígonos industriais, absorvendo força de trabalho da agricultura, localizada no interior dos municípios e perto das novas fábricas com uma renovada acumulação do capital através de uma prática do século XIX, ou seja, a expropriação e a proletarização do exército de reserva feminino ainda existente no interior garantindo trabalhadoras sem ligações com reivindicações laborais ou sindicatos.

"Y yo creo que en este pueblo que debe tener 15 mil habitantes, 15 mil debe tener Poio, yo creo que todo el mundo tiene un primo o un familiar que pasó por esta empresa hace 50 años. Seguro, seguro. Porque como contrato muchos eventuales." (G, 23/05/2012).

As mulheres executam atividades plurais nas fábricas que não são contabilizadas em termos salariais. As entrevistas indicam que os salários baixos são uma constante ao longo dos anos.

"Las señoras empaquetan, están en la máquina, empacan, descongelan, cuecen. Saben hacer de todo. Y hecho en esta empresa intentamos que todos sepamos hacer de todo." (G, 23/05/2012).

“(...) que hagas que no hagas cobras igual pero... Claro la cantidad hay... hay que hacerla." (M, 07/07/1995).

A maioria dos homens ainda detém os contratos permanentes e as mulheres, à exceção das trabalhadoras fixas, são força de trabalho eventual, que depende das demandas sazonais do pescado. A situação de trabalho das mulheres passa pelos contratos implícitos e individuais a contratos explícitos e coletivos com algumas melhorias das condições laborais.

“(...) si somos ahora mismo aquí pues sobre 180 , ya te digo que el $70 \%$ somos mujeres y casi más el $80 \%$. El $80 \%$. Yo cada vez que se contrata, salvo el equipo de mecánicos que sigue siendo hombres, porque no hay muchas mujeres, lo demás de aquí pueden ser mujeres." (G, 23/05/2012). 
$\mathrm{Na}$ Galícia, a indústria de produtos da pesca tem como base um sistema desigual de contratação de homens e mulheres. Até às últimas décadas do século XX, a maioria dos homens tinha contratos permanentes e, as mulheres detinham dois tipos de contratos: as trabalhadoras fixas, com contratos permanentes e, no período de safra, as trabalhadoras fixas-descontínuas com contratos eventuais. Os anos de 1980 marcaram um período de abertura política e a possibilidade de atender, através da legislação, às reivindicações laborais por melhores salários, condições e relações de trabalho. As reivindicações associadas às lutas por igualdade de condições entre trabalhadoras e trabalhadores contou com a participação efetiva das mulheres. O resultado foram leis para dirimir a histórica desigualdade no mundo do trabalho remunerado. Porém, no setor da conserva de pescado ainda que a profissão esteja reconhecida pela Classificação Nacional de Ocupações, os avanços em termos salariais são irrisórios. Os baixos salários permanecem até ao século XXI. O Boletín Oficial del Estado (2011) indicou que as trabalhadoras do Sector de conservas, semiconservas, ahumados, cocidos, secados, elaborados, salazones, aceite $y$ harina de pescados y mariscos trabalhavam majoritariamente no chão de fábrica. E faziam parte do quinto grupo denominado Personal de fabricacion recebendo um salário mínimo em torno de 905 Euros. Em contraponto, o sexto e último grupo composto em sua maioria por homens do setor Personal de ofícios vários, menos especializados, recebia 950 Euros.

Os salários baixos indicam trabalhadoras e trabalhadores explorados dentro da lógica empresarial que permeia o setor da conserva da pesca com uma desvalorização do trabalho realizado. Os salários desiguais entre mulheres e homens são consequência da divisão de trabalho por gênero na lógica patriarcal. Independente do sexo, a opressão das mulheres é reforçada, muitas vezes, pelas próprias mulheres que reproduzem o discurso patriarcal naturalizando a segregação laboral. MC tem claro que se tivesse que contratar pessoas para "la tarea de enalatar o desconchar", supunha que contrataria mulheres, "porque es lo que se está acostumbrado" (MC, 13/07/1995). Outra entrevistada ao responder sobre o porquê de mecânicos ou encarregados serem homens, responde que "(...) los hombres hacen las cosas que no podemos hacer nosotras" (C, 18/07/1995). Porém ao ser questionada em relação à afirmativa, respondeu que as mulheres poderiam, com algum nível e tempo de aprendizado, realizar as tarefas tradicionalmente realizadas pelos homens.

Em 2012, em uma das visitas às fábricas, foi possível identificar uma trabalhadora conduzindo uma máquina empilhadeira, atividade que em regra era e é praticada por homens. Ou seja, no chão de fábrica, se há indícios de quebra dos padrões históricos, onde as mulheres eram responsáveis apenas pelas tarefas ligadas ao manuseio do pescado e a limpeza do ambiente fabril, elas também demonstram habilidades em outras funções. No entanto, a desigual divisão do trabalho por gênero ainda é a regra, dificultando a possibilidade das mulheres obterem cargos de direção ou chefia. Nas entrevistas realizadas com duas mulheres que ocupavam cargos de direção, identifica-se que a mentalidade patriarcal sofreu impactos nos últimos vinte anos oriundos da luta feminista que impregna o discurso. É importante salientar que elas faziam parte da família dos proprietários da fábrica e eram responsáveis pela continuidade aos negócios familiares. No testemunho 
abaixo, está um registro que as trabalhadoras do chão de fábrica estão satisfeitas e não precisam de associações para a realização de reivindicações laborais pois a fábrica é considerada como uma família:

“¡bueno están encantadas! De hecho en esta empresa no hay sindicatos. No los quiere el personal. [por quê?] Porque estamos felices y trabajamos como una familia." (Diretora de empresa, 2012).

O discurso feminista das diretoras também mostrou a mentalidade liberal e conservadora que reforça a desigualdade entre as mulheres de classes sociais diferentes e que dificulta a busca pela igualdade no mundo do trabalho e a eliminação a exploração.

\section{Trajetórias de resistência}

As trabalhadoras demonstraram práticas de resistência individuais, como indicações de dores de cabeça e frequência no uso do banheiro para garantir descanso durante a jornada de trabalho. Entretanto, foco do tópico são as ações de resistência coletiva das trabalhadoras galegas. Até ao final do século XIX, as trabalhadoras galegas não protagonizaram nenhum conflito nem eram associadas aos sindicatos. Os primeiros trabalhadores que se organizaram em associações foram os soldadores de Vigo, participando das primeiras greves, em 1890. A sazonalidade da indústria, a eventualidade do trabalho e o analfabetismo da maioria dificultaram a criação de associações de trabalhadoras no setor. O trabalho intermitente dificultava a criação de vínculos, mas o ambiente machista das associações e sindicatos também acarretou a menor participação das mulheres, como as limitações ao direito de associação em alguns estatutos (Pereira, 1992).

No final de 1899, La Federación de Trabajadores de Vigo, aglutinava várias associações de trabalhadores, entre eles os das fábricas de conserva. No início do século XX as trabalhadoras se organizaram em associações. Segundo Muñoz Abeledo (2002, p. 144), a Unión de Trabajadores de las Fábricas de Conservas de la Ría de Vigo foi um dos primeiros sindicatos que agrupavam trabalhadores/as dos municípios próximos. Os homens ocupavam os cargos principais e as mulheres eram suplentes.

De acordo com Muñoz Abeledo (2010), durante as primeiras décadas do século XX, os conflitos e os salários mais baixos das mulheres estavam relacionados com a segregação laboral, e as condições de trabalho que, muitas vezes, estavam baseadas no assedio sexual e nas questões sobre seguro maternidade ${ }^{\text {viii. }}$. As trabalhadoras obtiveram alguns ganhos a partir da 1919, advindas da Conferencia Internacional da Organização Internacional do Trabalho (OIT) em Washington que propôs o seguro maternidade, ratificado pela Espanha em 1922. Os benefícios ligados à maternidade eram pagos em parte pelos empresários e em parte pelas trabalhadoras que realizaram paralizações das atividades protestando contra esta modalidade que diminuía o salário final.

Até aos anos trinta do século XX os sindicatos eram herdeiros das associações de profissões masculinas e ainda que englobassem as mulheres, reforçavam a segmentação do trabalho industrial e os ofícios realizados por elas eram considerados de baixo status. 
Porém, deve-se questionar a concepção de que os movimentos de resistência como as greves, os motins e as paralisações eram essencialmente masculinos e que as mulheres eram menos combativas e que sua intervenção seria indireta, freando ou incentivando seus maridos ou pais. Primeiro, porque as mulheres das classes populares protagonizaram episódios de resistência e algumas, como as estivadoras, trabalhavam em ofícios considerados masculinos. Segundo, havia a ocultação dos movimentos pela imprensa que enaltecia o caráter passivo das trabalhadoras (Pereira, 1992, 2010). Algumas mulheres galegas protagonizaram reivindicações e lutas por igualdade social e condições de trabalho. Em 1931, em Vigo, durante um mês, mais de 4000 trabalhadoras pararam as fábricas de conservas. O movimento ocorreu nas rías de Vigo especificamente na fábrica Alfageme e depois em todo litoral galego. A greve reivindicava uma jornada de trabalho justa e catalisou outros movimentos sociais, como os trabalhadores navais, levando os sindicatos a promoverem uma greve geral de três dias em toda a Galícia.

De 1940 a 1980 a maioria das trabalhadoras das fábricas de conserva não eram computadas nos registros oficiais, apesar de trabalharem desde jovens. Na pesquisa dos censos foram inscritas como donas de casa e, em muitas fábricas não eram registradas como trabalhadoras. No período da ditadura franquista (1939-1976), a imposição de um modelo familiar patriarcal impôs a divisão sexual tradicional do trabalho. Para as sociedades patriarcais, a remuneração das mulheres é complementar e a sua presença é mais importante na reprodução, enquanto aos homens lhes cabe o papel de provedores da família ${ }^{\text {ix }}$. Quando as mulheres trabalham como assalariadas, estão predominantemente nos setores de serviços e comércio e nas atividades informais, temporárias e precárias ou em setores de atividades formais, mas de baixa remuneração (Massey, 1984; Harvey, 1992).

A década de 1980 foi iniciada com os desacordos entre Unión General de Trabajadors (UGT) e a central sindical galega, a Intersindical Nacional Galega (ING) ${ }^{\mathrm{x}}$. As propostas da UGT e da patronal não representavam melhorias para as trabalhadoras, que viam negativamente a nova lei de emprego de 180 dias de trabalho efetivo e o seguro desemprego (Ley Basica de Empleo). De acordo com a ING, 4636 trabalhadoras fijas-discontinuas seriam prejudicadas com a nova lei, pois ficavam três meses sem receber.

No final da década de 1980 o panorama político e econômico trouxe outros desafios. Em 1986, as trabalhadoras da fábrica Massó Hermanos em Cangas (Pontevedra), protestaram contra a demissão de três empregados fijos-discontínuos da empresa. A direção fechou a fábrica em resposta à paralisação dos trabalhadores. A decisão dos empregados surpreendeu a UGT, que manifestou "total desacuerdo con la ocupación ilegal de la empresa por la INTG, que puede suponer un irreparable perjuicio para todos los trabajadores" (Intersindical Nacional dos Trabalhadores Galegos, 1986). Na fábrica Massó em Cangas, trabalhavam 376 operários, dos quais 220 eram fixos descontínuos (Palmero, 1986). A saga das trabalhadoras se estende até meados dos anos noventa, quando a fábrica foi hipotecada e desativada.

Em 1989, as trabalhadoras protagonizaram a ocupação (encierre) da fábrica Odosa na Illa de Arousa. Os depoimentos abaixo indicam o drama vivido pelas mulheres para 
conservar seus empregos e foram extraídos do documentário de Permui (2011), denominado Doli, doli doli, coas conserveiras. Rexistro de traballo. As falas das trabalhadoras são representativas da situação que se perpetua.

"A las conserveras nos infravaloraron siempre, nos arrinconaron, ahora no es tan des-
carado como antes, pero sigue funcionando. Con fuerte inversiones públicas, que paga-
mos todos los galegos (nueve millones de euros), los empresarios se comprometen a
reabrir los centros de Ribadumia y Vilaxoán, en el Salnés, y garantizar 150 puestos de
trabajo. Pero nos quitan nuestros derechos de trabajadoras fijas para hacernos fijas dis-
continuas, o sea que nos llamarán para trabajar sólo cuando lo crean necesario, y
durante cinco años." (B, la primera sindicalista de la secular fábrica ahora cerrada de
Odosa, en Illa de Arousa, 2011).
"Nos cambian trabajos dignos y decentes por precarios, y encima tenemos que aplau-
dirles. ¿Dónde está el avance? Estamos casi como cuando cerró Odosa." (L, 2011).
"Te ponían en el seguro con el nombre de otra. Te mandaban cantar para que no comie-
ras el marisco que enlataban. Hasta el cierre, en 1989, los aseos de señora en la fábrica
estaban restringidos, cerrados con llave. No existían, el sueldo de conservera era como
un complemento del marido, cuando era en muchas ocasiones el único sustento de la
economía familiar." (DD, 2011).

Na primeira década do século XXI, empresas como Conserva Burela, Peña e Alfageme são exemplos que mostram que a luta das trabalhadoras é contra o fechamento das fábricas, pela manutenção do trabalho e não está relacionada com a criação de formas alternativas de administração. As fábricas foram vendidas para a construção de hotéis ou loteamentos aproveitando a localização em áreas litorâneas com amplas possibilidades para atividades terciárias. Em 2013 foi encerrada a saga das trabalhadoras da Alfageme de Ribadumia e de Vilaxoán que resistindo em frente a fábrica, buscavam alternativas junto aos empresários e a Consellería de Economía e Industria da municipalidade. A estratégia da empresa foi a venda das máquinas, inviabilizando a recuperação dos postos de trabalho, o que sobrou ficou a mercê de ladrões e definitivamente o plano de reativação da fábrica foi encerrado (Gonzáles, 2013).

As ações das trabalhadoras da Alfageme representaram e representam um símbolo de resistência. O símbolo reforça a necessidade de resistir para manter o trabalho, para ter salários dignos e para não sucumbir às restruturações que os agentes públicos e/ou privados promovem considerando unicamente a lógica fabril e os interesses empresariais fechando e/ou deslocando fábricas com consequências diretas para os trabalhadores/as.

\section{CONSIDERAÇÕES FINAIS}

Os processos de configuração e de reconfiguração das lógicas organizativas das relações sociais ao longo do tempo indicam a centralidade da combinação entre o trabalho, o Estado moderno e os diferentes agentes, especialmente as empresas. A centralidade do 
trabalho para a produção, impõe a busca de estratégias e a construção de marcos regulatórios para a manutenção e a reprodução do modo de produção capitalista em diferentes recortes territoriais. Desta forma, é imperioso que as análises sobre o mundo trabalho considerem diferentes realidades em suas múltiplas escalas bem como compreendam as relações que separam e aproximam contraditoriamente o capital e trabalho com os regramentos estatais considerados como diferentes agentes e as suas marcas sociais como gênero e classe social. Este artigo, baseado em ampla pesquisa bibliográfica e de atividades de campo com entrevistas, identificou e analisou as ligações entre o trabalho e os agentes hegemônicos do setor industrial de pescado com destaque mundial: as empresas instaladas na Galícia.

$\mathrm{Na}$ pesquisa, o trabalho feminino assalariado foi considerado como ainda marcado, majoritariamente, pela segregação laboral que se repercute nos salários mais baixos. Na indústria de produtos da pesca, as explicações devem combinar questões econômicas e políticas que afetam o setor e a reflexão feminista com aporte conceitual que considera o patriarcado e as relações de gênero. $\mathrm{O}$ trabalho das mulheres nas fábricas galegas, perpetua algumas das características do processo: segregação sexual, baixos salários, insegurança derivada das ações patronais e baixo status da profissão. $\mathrm{O}$ trabalho ainda é essencialmente manual, com algumas exceções, como determinadas fases do beneficiamento do atum para enlatamento que tende para a mecanização. A pesquisa apontou um aumento da presença masculina no chão das fábricas que automatizam algumas partes da produção como a limpeza e o enlatamento do pescado, que historicamente foi realizado de forma manual pelas mulheres. De forma combinada foi identificada a presença de mulheres em cargos diretivos. Porém a combinação do aumento do trabalho masculino no chão da fábrica com o feminino na administração superior das empresas, não altera as características gerais do processo em relação ao conjunto dos trabalhadores(as) posto que as diretoras têm suas trajetórias ligadas as famílias dos proprietários das fábricas.

De maneira geral o setor mantém um caráter de exploração da força de trabalho feminina, seja através dos baixos salários e do uso sazonal de trabalhadoras ou com o deslocamento territorial das fábricas, que possibilita a substituição de trabalhadoras galegas mais politizadas por trabalhadoras de áreas agrícolas ou de outros continentes com pouca experiência sindical e de práticas de reivindicações laborais.

Os deslocamentos das fábricas de pescado de empresas com sede na Galícia para outros países e continentes em especial para a América Latina e África, impacta significativamente no número de trabalhadoras galegas diminuindo sua histórica capacidade de resistência e de luta por melhores condições laborais e salariais. No conjunto, a lógica de reprodução das empresas disputando as melhores localizações para a construção de indústrias com capacidade de recebimento de grandes volumes de matéria-prima de todos os oceanos com características de commodities e a produção de milhões de latas de pescado por dia, carrega consigo o acirramento da lógica da exploração do trabalho feminino que deve encarar suas lutas não apenas no chão de cada fábrica, mas nas escalas nacional e mundial. 


\section{AGRADECIMENTOS}

Os autores agradecem a Coordenação de Aperfeiçoamento de Pessoal de Nível Técnico Superior (CAPES) do Brasil pela concessão das Bolsas de Pós-Doutorado no exterior e ao Departamento de Geografia da Universitat Autónoma de Barcelona pelo acolhimento e apoio para realização das pesquisas em 2012, em especial aos professores Antoni Francesc Tulla Pujol e Maria Dolors Garcia Ramón.

\section{REFERÊNCIAS BIBLIOGRÁFICAS}

Aoyama, Y., Murphy, J., \& Hanson, S. (2012). Key Concepts in Economic Geography. Los Angeles/London: Sage.

Alcubilla, P. (2012). Lineal de conservas de pescado: entre las grandes marcas y la MDD. Madrid: Alimarket-alimentácion.

Bauman, Z. (2015). A riqueza de poucos beneficia todos nós? Rio de Janeiro: Zahar.

Beneria, L. (1979). Reproduction, production and the sexual division of labor. Cambridge Journal of Economics, 3(3), 203-225.

Beuren, I., \& Cardoso, R. (2010). Gestão de custos de matérias-primas em indústrias de conserva de pescado do Brasil e da Espanha. ABCustos Associação Brasileira de Custos, 2, 1-16.

Boletín Oficial del Estado. (2011). 57. Espanha: Ministerio de Trabajo y Inmigración

Carmona Badía, X. (2011). (Ed.) Las famílias de la conserva. El sector de las conservas de pescado a través de sus sagas familiares. Pontevedra: ANFACO-CECOPESCA-Fundación Cluster de Conservación de Productos del Mar.

Díaz de Rábago, J. (1885). La industria de la pesca en Galicia. Santiago: Fundación Pedro Barrié de La Maza.

Elson, D., \& Pearson, R. (1981). Nimble fingers" Make Cheap Workers': an Analysis of Women's Employment in Third World Manufacturing. Feminist Review, 7, 87-107.

Foord, J., \& Gregson, N. (1986). Patriarchy: towards a reconceptualisation. Antípode, 18, 186-211.

Garcia, Ramon, M. D. (1990). La división sexual del trabajo y el enfoque de género en el estudio de la agricultura de los países desarrollados. Agricultura y Sociedad, 55, 251-277.

Gonzáles, M. (2013). El liquidador judicial de Alfageme estudia ofertas sobre las fábricas de O Grove y Vigo. Faro de Vigo. Disponível em: http://www.farodevigo.es/portada-arousa/2013/12/02/liquidador-judicial-alfageme-estudia-ofertas/925023.html

Hartmann, H. (1976). Capitalism, patriarchy, and job segregation by sex. Signs, 1(3), 137-169.
Hartmann, H. (1980). Un matrimonio mal avenido: hacia una unión más progresiva entre marxismo y feminismo. Zona Abierta, 24, 85-113.

Harvey, D. (1992). A condição Pós-Moderna. Uma pesquisa sobre as origens da mudança cultural. São Paulo: Loyola.

Instituto Nacional de Estadística. (2010). Mujeres y hombres en España. Madrid: INE.

Intersindical Nacional dos Trabalhadores Galegos. (1986). Arquivo Mera. Santiago de Compostela: INTG.

Martins, C. A. (2006). Indústria da pesca no Brasil: o uso do território por empresas de enlatamento de pescado. (Dissertação de doutoramento). Disponível em: https://repositorio.ufsc.br/xmlui/bitstream/123456789/88366/1/231199.pdf

Massey, D. (1984). Spatial divisions of labour: social structures and the Geography of production. London: Macmillan.

Massey, D. (2004). Geographies of Responsibility. Geografiska Annaler, 86(1), 5-18.

McDowell, L., \& Pringle, R. (1992). (Eds.) Defining Women. Social Institucions and Gender Divisions. Cambridge/Oxford: Polity Press/ The Open University.

McDowell, L., \& Sharp, J. (1997). (Eds.) Space, Gender, Knowledge. Feminis Readings. London: Arnold.

Mitchell, J. (1975). Pyschoanalysis and Feminism. New York: Vintage Book.

Muñoz, Abeledo, L. (2002). Los mercados de trabajo en las industrias marítimas de Galicia. Una perspectiva histórica, 1870-1936. (Dissertação de doutoramento) Disponível em: http://ddd.uab.cat/ record/37229

Muñoz Abeledo, L. (2010). Género, trabajo y niveles de vida en la indústria conservera de Galícia: 1870-1970. Barcelona: Editorial Icária.

Núnez Gamallo, R. (2006). Las empresas conserveras y el mercado mundial de atún. Revista Galega de Economía, 15, 1-20.

Pateman, C. (1988). The sexual contract. Stanford: University Press. 
Pereira, D. (1992). (Ed.) Os conquistadores modernos. Movemento Obreiro na Galicia de anteguerra. Vigo: Edicións A Nosa Terra.

Pereira, D., Diéguez, U., \& Máiz, B. (2010). Síntese Histórica do Movemento Obreiro Galego. Das orixes até 1984. A Coruña: FESGA - Confederación Intersindical Galega (CIG).

Permui, U. (2010). Doli, doli doli, coas conserveiras. Rexistro de traballo. Uqui Permui, prod. e dir. Santiago de Compostela: Axencia Galega das Industrias Culturais. Disponível em: http://elpais.com/diario /2011/04/01/galicia /1301653111 850215.html

Piketty, T. (2014). O capital no século XXI. Rio de Janeiro: Intrínsica.

Saffioti, H. (2000). Quem tem medo dos esquemas patriarcais de pensamento? Dossiê Crítica Marxista, 11, 71-75.
Saffioti, H. (2004). Gênero, patriarcado, violência. (2a ed.). São Paulo: Fundação Perseu Ábramo.

Vainer, C. (2001). As escalas do poder e o poder das escalas: o que pode o poder local? Anais do IX Encontro Nacional da ANPUR, 1, 140-151.

Young, I. (1981). Beyond the unhappy marriage: a critique of the dual systems theory. In L. Sargent, (Ed.), Women and revolution, a discusion to yhe unhappy marriage of marxismo and feminism (pp. 43-69). Boston: South end Press.

Young, I. (1992). Marxismo y feminismo, más allá del "matrimonio infeliz" (una crítica al sistema dual). El cielo por asalto, II(4). 1-17. Retrieved from: http://www.democraciasocialista.org/wp-content/ uploads/2014/03/139104361-Young-Marxismo-y-feminismo.pdf

i Asociación Nacional de Fabricantes de Conservas de Pescado y Marisco y o Centro Técnico Nacional de Conservación de Productos de la Pesca (ANFACO/CECOPESCA) com sede em Vigo remonta a "Unión de Fabricantes de Conservas de la Ría de Vigo", associação empresarial criada em 1904. A entidade é segunda organização empresarial mais antiga da Espanha e esta relacionada, sobretudo, aos conflitos que existiam com os pescadores por preços do pescado e com os trabalhadores fabris. As cerca de 200 empresas associadas a ANFACO/CECOPESA empregam aproximadamente 25 mil trabalhadores e comercializam seus produtos nos cinco continentes.

ii No artigo, emprego é considerado como trabalho assalariado disponível no mercado de trabalho e aquele que envolve a formalização de uma relação pactuada. O trabalho remunerado envolve um pagamento, mas não necessariamente o registro formal.

iii Pesquisas realizadas na Espanha durante os estágios de pós-doutorado em 2012-2013 no Departamento de Geografia da Universitat Autónoma de Barcelona (UAB), como bolsistas da Coordenação de Aperfeiçoamento de Pessoal de Nível Superior do Brasil: MARTINS, C. A. "Indústria de enlatamento de pescado no Brasil e na Espanha: estudo comparativo da estrutura empresarial e territorial”; VELEDA DA SILVA, S. "As mulheres trabalhadoras das fábricas de preservação e fabricação de produtos de pescado: um quadro comparativo entre Brasil e Espanha”. No artigo foram utilizados elementos da pesquisa coordenada por Maria Dolors Garcia Ramon: Contexto regional y relaciones de género en la reorientación de las actividades rurales en España.Un análisis desde la Geografía, financiada por DGCICYP e realizada em parceria entre a UAB, a Universidad de Santiago de Compostela, a Universidad de Sevilla, Universidad de Valencia e a Universidad de Girona no período de 1994-1997. Os autores agradecem as pesquisadoras Montserrat Villarino Pérez (USC) e María Dolors García Ramon (UAB) por cederem as transcrições das entrevistas.

iv $\mathrm{O}$ artigo refere-se às trabalhadoras incluídas na Clasificación Nacional de Actividades Económicas (CNAE) de 2009 e inclui o grupo "fabricación de conservas de pescado" na divisão "procesado y conservación de pescados, crustáceos y moluscos".

Ver http://www.ine.es/daco/daco42/clasificaciones/cnae09/cnae2009.pdf

$\checkmark$ Dados da Food and Agriculture Organization (FAO). Fisheries and Aquaculture Information and Statistics Service, 2012-2013.

vi Para o Instituto Nacional de Estadísticas (INE) de Espanha, uma empresa pode ter mais de um estabelecimento que equivale as fábricas. Em 2010 o INE contabilizou 552 empresas e 886 estabelecimentos (www.ine.es)

vii Os dados foram complementados com as pesquisas de campo nas empresas na Galícia, na sede da ANFACO, jornais galegos e na revista Indústria Conservera. A quarta maior empresa é a Garavilla com sede em Mundaka que em processo de reestruturação foi descartada em função da inconstância na divulgação de seus dados.

viii O seguro maternidade foi definido pelo Real Decreto Ley sobre el Seguro de Maternidad em 22 de março de 1929, com o objetivo de "Garantizar á la asegurada la asistencia facultativa en el embarazo y en el parto y cuando, con ocasión de uno u otro, la necesitare; b) Garantizar los recursos necesarios para que pueda cesar en su trabajo antes y después del parto; y c) Fomentar la creación y sostenimiento de Obras de Protección á la Maternidad y á la Infancia” Ver http://www.ub.edu/ciudadania/hipertexto/evolucion/textos/social1929.htm

ix A OIT recomenda a necessidade de superar a visão da mulher como "força de trabalho secundária".

Ver http://www.oit.org.br/info/downloadfile.php?fileId=442

x A UGT é uma organização sindical criada em 1888 e possui atuação em todos os setores do conjunto do território espanhol. A ING é uma organização intersindical nacionalista da Galícia criada em 1977. 